\title{
MODELING OF STENT EXPANSION DYNAMICS AND RESULTANT ARTERIAL WALL AND LESION STRESSES IN A STENOSED ARTERY
}

\author{
M.R. HYRE ${ }^{1}$, S.A. CHAE $^{1}$ \& R.M. PULLIAM ${ }^{2}$ \\ ${ }^{1}$ Department of Mathematics and Engineering, Northwestern College, Orange City, IA, U.S.A \\ ${ }^{2}$ Department of Mechanical Engineering, Villanova University, Villanova, PA, U.S.A.
}

\begin{abstract}
Restenosis remains a significant problem in coronary intervention. Additionally, concerns have recently been raised that drug eluting stents (DES) are linked to long-term thrombosis. For carotid artery stenting, the most serious complication is ipsilateral neurologic events due to an acute embolus from fragmentation of the lesion during stent deployment.

While much attention has focused on biocompatibility solutions to these problems, less attention has been given to matching stents to the inflation balloon, atherosclerotic plaque mechanical properties, and lesion shape. Results show that the risk of arterial damage or plaque fractures is dependent on plaque morphology and material properties. Computational modeling results also indicate that it may be possible to use numerical simulations to estimate stress distributions in atherosclerotic lesions in vivo during and after stent deployment. This may help provide clinical indicators in stenting to reduce vascular injury and plaque rupture, which can cause acute and long-term post-procedural lumen loss in coronary artery stenting or stroke in carotid artery stenting.

Results also indicate that while a complex model for plaque morphology is necessary to determine the stress distribution within the lesion, a more simple homogeneous plaque model will allow for reasonably accurate predictions of arterial stresses.

Keywords: Finite element analysis, plaque, restenosis, stent, vascular injury.
\end{abstract}

\section{INTRODUCTION}

Coronary artery disease (CAD) is the leading cause of morbidity and mortality in the United States, and it is estimated that the absolute mortality due to CAD will increase as the average age of the population rises [1]. Atherosclerotic stenosis and its ischemic complications necessitate arterial reconstruction. Current strategies to restore normal blood flow in stenosed coronary arteries include angioplasty, intracoronary stents, and coronary artery bypass surgery.

For coronary stent implantation, restenosis is the most common complication. The incidence of restenosis is high, with nearly $25 \%$ experiencing complications after stenting [2]. The mechanisms of restenosis are complex and not well understood. Most theories suggest that restenosis is a response of the artery to the trauma induced by balloon inflation and stent deployment. This causes thrombosis, inflammation, cellular proliferation, and extracellular matrix production, which leads to lumen loss [3]. Therefore, restenosis remains a significant problem in coronary intervention.

More recently, concerns have been raised that drug-eluting stents (DES) are linked to long-term thrombosis. There is growing evidence that shows in-stent macrophage infiltration and death, leading to the formation of a necrotic core and thus a vulnerable lesion. These were most commonly seen when the stented lesion had underlying ruptured plaque, or thin-cap fibroatheroma [4-8]. Arterial healing at the lesion site in acute myocardial infarction (AMI) patients treated with DES is substantially retarded when compared with patients with stable anginas [9-11]. This reinforces the need to understand plaque morphology and lesion/arterial response to DES deployment.

Advances in prosthetic science and engineering have spurred the rapid development of many new permanent implants. These devices are typically attached to a delivery catheter and threaded to the site of interest where they are expanded. The very nature of the remote delivery systems make the 
mechanical details of implantation difficult to ascertain, yet this is important to quantify since there may be a link between how the devices are emplaced and the body's acute and chronic response. For example, carotid artery stenting is now an alternative to treating atherosclerotic stenosis of the internal carotid artery to prevent stroke [12-15]. As opposed to coronary artery stenting, the most serious complication of stent placement for ICA stenosis is neurologic events due to an embolus from fragmentation of the atherosclerotic lesion during stent deployment. Current stent deployment methods are designed to block or trap larger fragments but may not completely eliminate microemboli [16, 17].

These studies suggest that an upper limit exists to the success of purely biomedical approaches for managing post-device implantation, and a return to examining the mechanical initiators of vascular injury and plaque rupture that occur during implantation. A better understanding of the mechanical

properties of plaques and arterial walls, and the manner in which they interact with stents and their delivery systems during deployment may lead to both a new understanding of the processes of vascular adaptation to implants and possibly to the design and development of less-injurious devices.

In order to evaluate the dynamics of stent deployment and the resultant stresses created in the plaque and arterial walls, a model must be constructed that includes both the stent and the balloon catheter. The effect of the delivery system can dramatically change the shape of the stent as it expands leading to regions of localized high stresses [18]. Currently, most finite element models only include the plastic deformation of the stent [19-22]. More recent models have included the plaque/artery system along with the stent but do not include the balloon catheter [23] or the inhomogeneous structure of the plaque and arterial wall [24]. There have been tremendous advances in the modeling of the mechanical behavior of plaques in coronary arteries [25-29]. However, these models were not designed to evaluate the interactions of stents with the plaque and arterial wall. This study presents a numerical simulation that includes the stent and balloon catheter system, along with a complex plaque and artery model. The problem is highly nonlinear and includes complex contact problems between the stent, balloon, plaque, and arterial wall.

\section{GEOMETRY}

The finite element stress analysis was performed on a three-dimensional stent/balloon/plaque/artery geometry. In addition to the usual difficulties in modeling the mechanical behavior of soft tissue, the overall system response is highly nonlinear due to the large plastic/multilinear elastic/hyperelastic deformations of the individual components. The component geometries and constitutive material models are described below.

\subsection{Artery}

The coronary artery modeled was $50 \mathrm{~mm}$ in length, with an intimal diameter of about $4.9 \mathrm{~mm}$. The arterial wall was composed of a $0.38-\mathrm{mm}$ thick intimal layer, a $0.77-\mathrm{mm}$ thick media layer, and a $0.935-\mathrm{mm}$ thick adventitia layer. The thicknesses were adapted from the work of Holzapfel et al. [30] for the plaque morphology described below (see Fig. 1). Average element size was about $0.5-\mathrm{mm}$ long with a thickness of $0.15 \mathrm{~mm}$. This configuration yielded a total of about 170,000 elements. The artery elements were defined by eight nodes capable of large deflections and hyperelasticity.

\subsection{Plaque}

The plaque structure was developed from intravascular MRI images [31]. The components of the arterial wall and the atherosclerotic plaque were distinguished by histomorphology and histochemistry. 


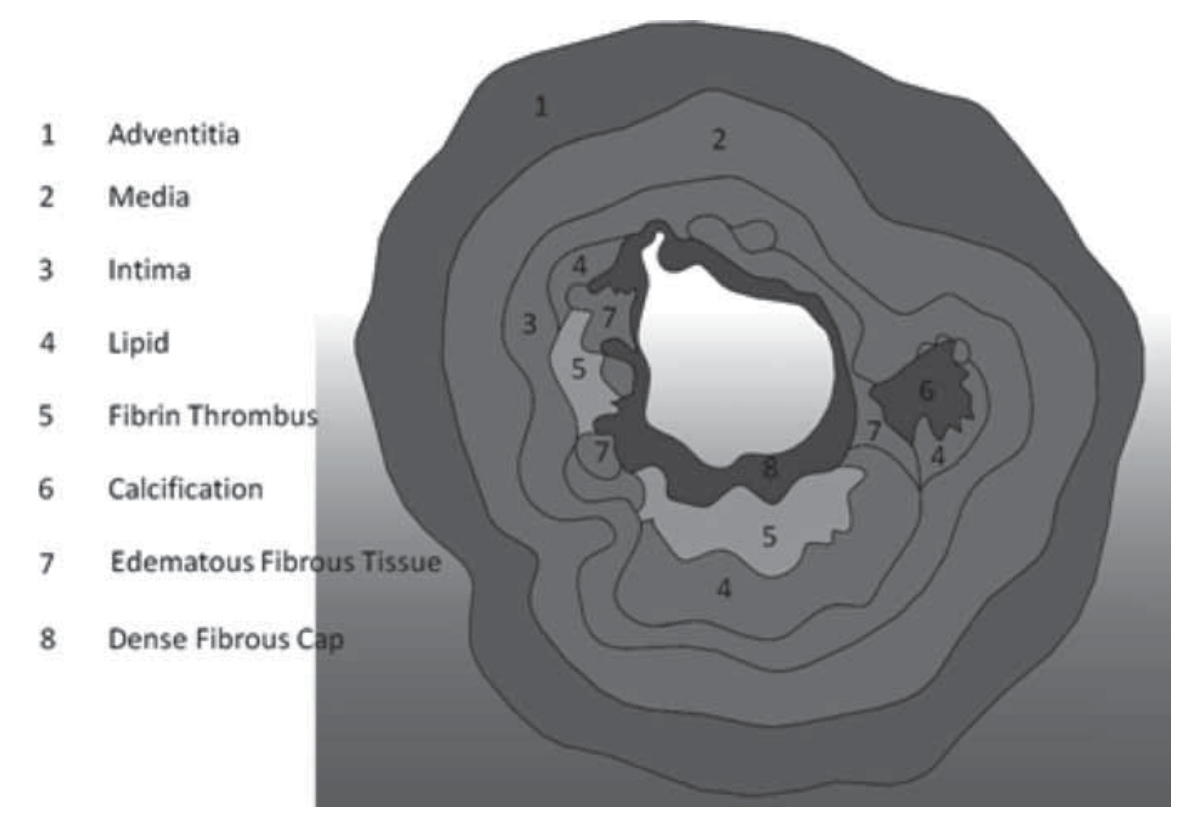

Figure 1: Plaque/artery cross-section.

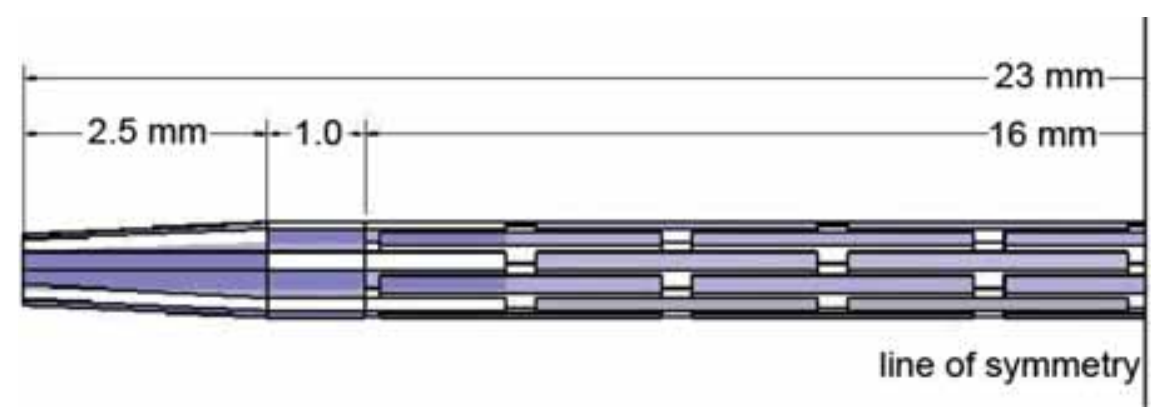

Figure 2: Balloon geometry, shown with mounted slotted tube stent.

For this study, five histological categories were used to describe the atherosclerotic plaque: (1) dense fibrous cap, (2) loose, edematous and fibrous tissue, (3) fibrin thrombus, (4) lipid, and (5) calcification. A cross-section of the plaque/artery geometry is shown in Fig. 1. The plaque was $30 \mathrm{~mm}$ in length and was assumed not to vary in the axial direction. This configuration corresponds to a maximum percent blockage of about $80 \%$. The plaque histological components can be seen in Fig.1.

\subsection{Balloon}

The balloon was modeled in its unfolded state, and already assumed to be in contact with the stent. The balloon dimensions are given at $0 \mathrm{~Pa}$, before stent expansion occurs. Depending on the amount of balloon overhang, the overall length of the balloon can range from 22 to $23 \mathrm{~mm}$. For 2-mm balloon overhang used in this study, the total length of balloon overhang is $2 \mathrm{~mm}$, or $1 \mathrm{~mm}$ on each side, yielding a total balloon length of $23 \mathrm{~mm}$ (see Fig. 2). 
The balloon was meshed using triangular shell elements with an average base size of $0.05 \mathrm{~mm}$ and an average side length of $0.05 \mathrm{~mm}$. This yielded 54,456 elements. The total balloon overhang was $2 \mathrm{~mm}$ ( $1 \mathrm{~mm}$ per side). For finite element analysis, elements capable of modeling shell structures, large deflections and plasticity were used.

\subsection{Stent}

A three-dimensional model of the slotted tube geometry intravascular stent was created. The stent is $16 \mathrm{~mm}$ in length (L), with an inside diameter (ID) of $1 \mathrm{~mm}$, and a thickness (t) of $0.1 \mathrm{~mm}$. The diamond-shaped stent consists of five slots in the longitudinal direction and 12 slots in the circumferential direction with a length of $2.88 \mathrm{~mm}$. The slots were cut such that in a cross-section, the angle describing the slot was approximately $23^{\circ}$, and the angle describing the metal between slots was $6.9^{\circ}$ (see Figs 3 and 4). These dimensions refer to the model in an unexpanded state [20, 22].

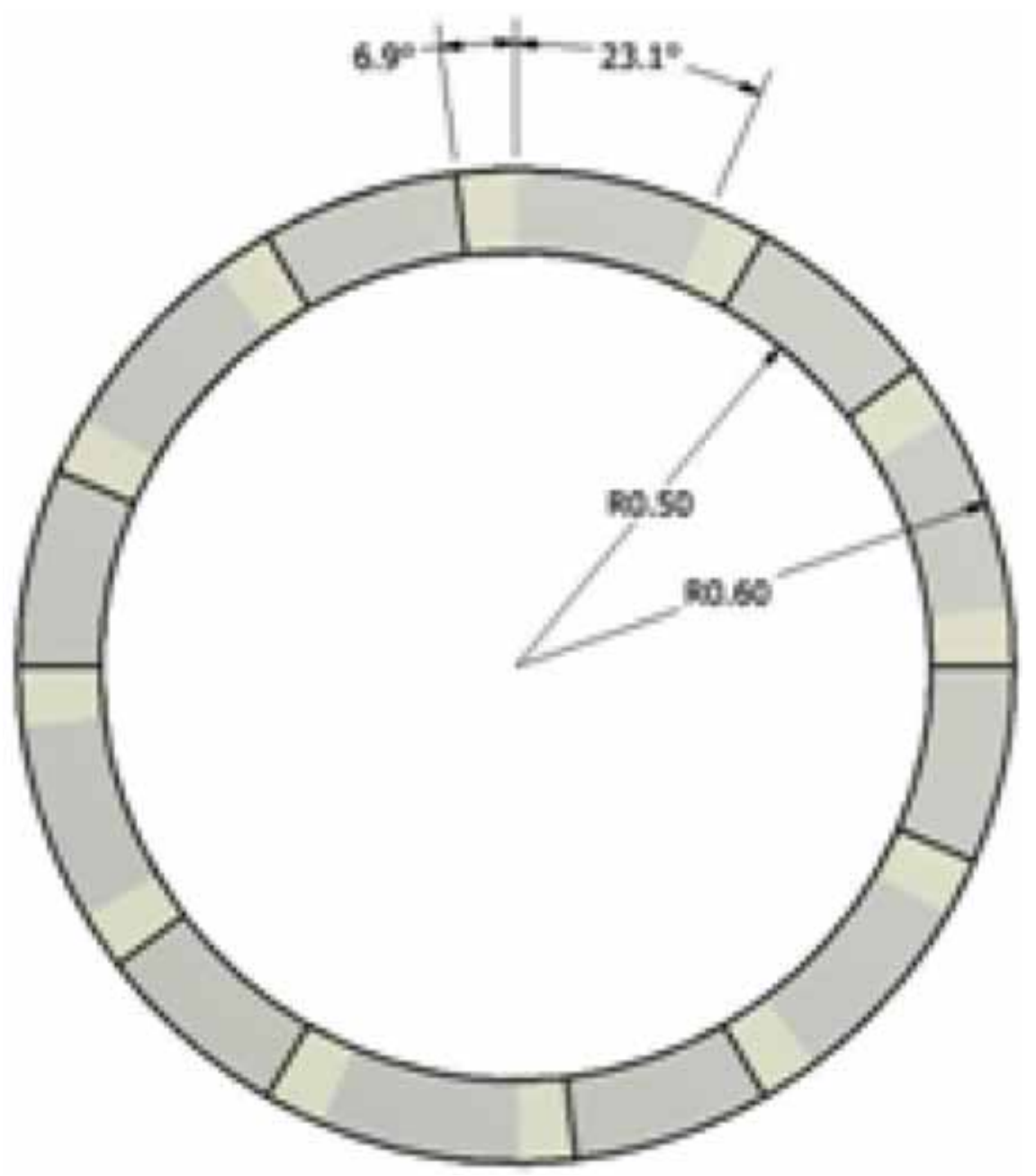

Figure 3: Medial slice of modeled slotted tube stent. 


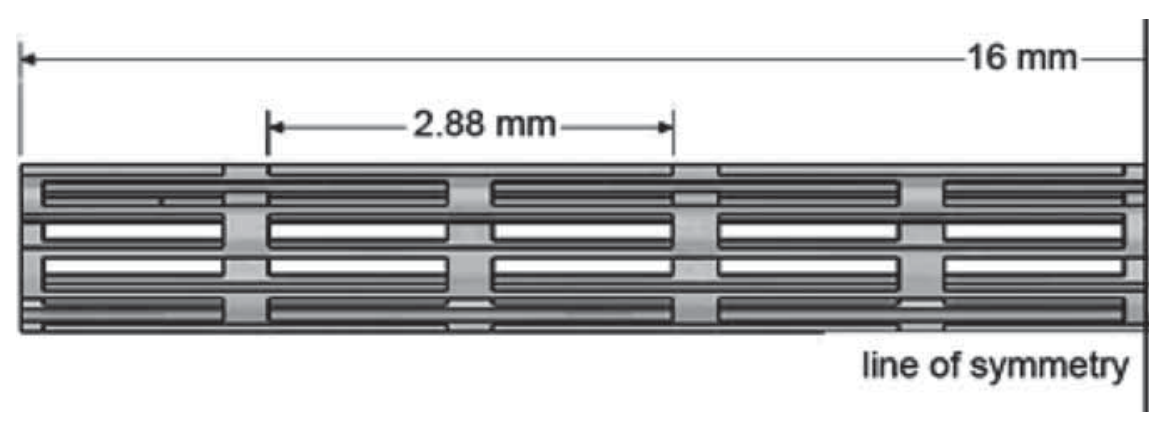

Figure 4: Side view - stent geometry.

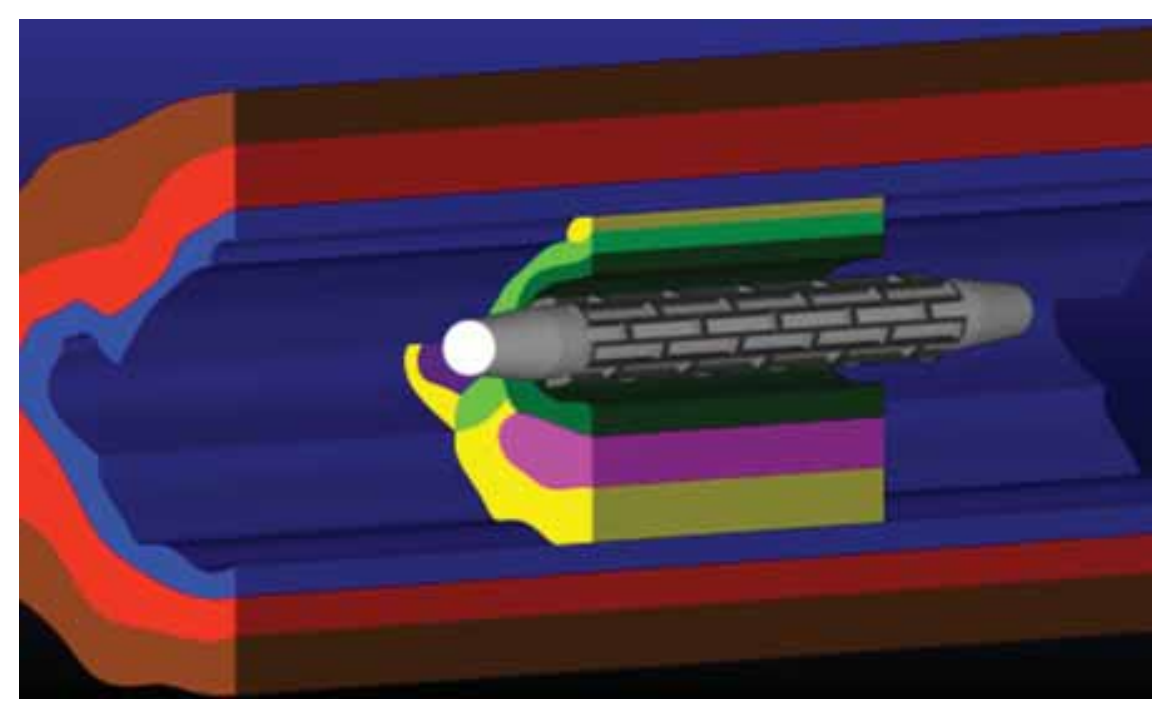

Figure 5: Final model geometry.

The stent was meshed using hexahedral elements. There are two elements through the thickness of the stent yielding a total of 12,036 elements. The stent elements are defined by eight nodes and are capable of large deflections and plasticity.

A cross-section of the final model geometry with the stent/balloon/artery and plaque cut away is shown in Fig. 5 (see Fig. 1 for component colors).

\section{MATERIALS}

\subsection{Artery}

The material properties of the artery are based on a previous study by Lagerqvist et al. [9]. They developed layer-specific mechanical properties of human coronary arteries with nonatherosclerotic intimal thickening. They fitted their data to a constitutive model that exhibits exponential stiffening at higher loads and allows for anisotropic effects. For this study, Holzapfel's data were fit to a standard Mooney-Rivlin hyperelastic constitutive equation. 
Table 1: Hyperelastic constants for arterial wall.

\begin{tabular}{cccc}
\hline & \multicolumn{3}{c}{ Arterial wall hyperelastic constants (MPa) } \\
\hline & Intima & Media & Adventitia \\
\hline $\mathrm{C}_{10}$ & 2.046 & -0.110 & -0.186 \\
$\mathrm{C}_{01}$ & -2.040 & 0.119 & 0.198 \\
$\mathrm{C}_{11}$ & 9.943 & 0.133 & 0.318 \\
\hline
\end{tabular}

Table 2: Material constants for plaque components.

Plaque hyperelastic constants (MPa)

\begin{tabular}{lccccc}
\hline & $\begin{array}{c}\text { Dense fibrous } \\
\text { cap }\end{array}$ & $\begin{array}{c}\text { Edematous fibrous } \\
\text { tissue }\end{array}$ & Fibrin thrombus & Lipid & Calcification \\
\hline $\mathrm{C}_{10}$ & -0.0968 & -0.0883 & -0.633 & & -3.025 \\
$\mathrm{C}_{01}$ & 0.0993 & 0.106 & 0.703 & & 3.107 \\
$\mathrm{C}_{20}$ & 14.648 & 0.114 & 0.757 & & 107.39 \\
$\mathrm{C}_{11}$ & -22.362 & 0.894 & & & -234.7 \\
$\mathrm{C}_{02}$ & 9.699 & -0.967 & & 0.00345 & 137.2 \\
$\mathrm{E}$ & & & & 0.45 & \\
$\mathrm{v}$ & & & & & \\
\hline
\end{tabular}

The Mooney-Rivlin strain density function used is given in the following equation:

$$
\mathrm{W}=\mathrm{C}_{10}\left(\mathrm{I}_{1}-3\right)+\mathrm{C}_{01}\left(\mathrm{I}_{2}-3\right)+\mathrm{C}_{20}\left(\mathrm{I}_{1}-3\right)^{2}+\mathrm{C}_{11}\left(\mathrm{I}_{1}-3\right)\left(\mathrm{I}_{2}-3\right)+\mathrm{C}_{02}\left(\mathrm{I}_{1}-3\right)^{3}
$$

where $\mathrm{W}$ is the strain-energy density function of the hyperelastic material. $\mathrm{I}_{1}, \mathrm{I}_{2}$, and $\mathrm{I}_{3}$ are the strain invariants. $\mathrm{C}_{\mathrm{ij}}$ are the hyperelastic constants. This model has been found to be suitable for modeling an incompressible isotropic material [32]. The program Hyperfit was used to generate the MooneyRivlin constants for a three-parameter strain density function (see Table 1).

\subsection{Plaque}

The material properties of the plaque are based on a previous study by Loree et al. [33]. As discussed above, five histological classifications of plaques were modeled. The data by Loree et al. were used to fit the Mooney-Rivlin hyperelastic constitutive equation for the dense fibrous cap, fibrin thrombus, and calcified plaque. The lipid was assumed to be linearly elastic, (nearly) compressible and isotropic. The data of Williamson et al. [34] were used to determine the circumferential Young's modulus. The loose, edematous, fibrous tissue was modeled as a soft cellular plaque from the data of Loree et al. This model for plaque behavior neglects anisotropy as well as the residual strain and active smooth muscle stresses. The constants were determined by fitting the three- or five-parameter Mooney-Rivlin expression to human aortic atherosclerotic tissue data. The hyperelastic and elastic constants for the plaque components are given in Table 2.

There is a large degree of uncertainty in the plaque properties due to the inherent variations between patients. However, sensitivity studies have shown that stresses within arterial walls, fibrous 
plaques, calcified plaques and lipid pools have relatively low sensitivities for variations in elastic modulus (when modeled as elastic and isotropic). Additionally, it was found that sensitivity to variations in elastic modulus is comparable between isotropic nonlinear, isotropic nonlinear with residual strains, and transversely isotropic linear materials [34].

\subsection{Balloon}

To model the mechanical properties of the balloon without evaluating the balloon's behavior during unfolding, empirical data were used. The stress-strain curve for the full expansion of the balloon produced a linear piecewise function. The first segment of the piecewise function is representative of the unfolding balloon, whereas the second is of the balloon expansion after unfolding.

\subsection{Stent}

The stent was modeled after the slotted tube geometry given by Migliavacca et al. [20]. This model assumes the stent to be made of $316 \mathrm{LN}$ stainless steel. The Poisson ratio is 0.3 and the Young modulus is $200 \mathrm{GPa}$.

\section{BOUNDARY CONDITIONS}

The artery, balloon, plaque, and stent were all constrained in the rotational directions allowing no rotation. The artery was constrained axially at the distal ends. The artery was at a minimum, 13.5-mm longer than the stent on each side and $17 \mathrm{~m}$ longer than the end of the balloon on each side. This constraint on the artery did not affect the behavior of the artery at the point of contact with the stent or balloon because of the extra length of the artery on both sides. The same axial constraint was placed on the balloon. To model the expansion of the balloon, the balloon was assigned a ramped internal pressure load.

\section{RESULTS AND DISCUSSION}

In vitro testing has shown that human atherosclerotic materials generally fracture under stresses in excess of $300 \mathrm{kPa}$ [35]. These findings were later confirmed using finite element modeling with histopathological correlations from specimens of ruptured plaque [36]. In this study, this stress level will be used as the indicator of plaque rupture. Figure $6 \mathrm{a}$ and $\mathrm{b}$ shows the intima stresses at the end of stent expansion for the complex plaque morphology along with a model where the plaque was assumed to be homogeneous with cellular plaque properties beyond the fibrous cap. There are obvious differences in the plaque stresses (especially in the region of the calcification). However, the maximum arterial stresses are not dramatically different.

Figure 7 shows the maximum intima von Mises stress during the expansion compared with the homogenous plaque model. The stresses predicted in the arterial layers are very similar. This confirms the results of previous studies [34]. Therefore, even though the plaque properties may vary significantly, the arterial stresses are not particularly sensitive to these variations.

Figures 8 and 9 show the maximum directional stresses for the dense fibrous cap and the intimal layer of the arterial wall during stent deployment.

Stresses in the fibrous cap are significantly larger than in the intima layer of the artery. All fibrous cap stresses exceed the fracture limit of $300 \mathrm{kPa}$ at the end of a 12-atm expansion pressure. The stresses in the media and adventitia layers are smaller than what is found since the intima is much more rigid. It should be mentioned that no plaque breakup model was included in the simulations. It may be the case that the fibrous cap would rupture before the higher stresses predicted by the model at the end of expansion. 


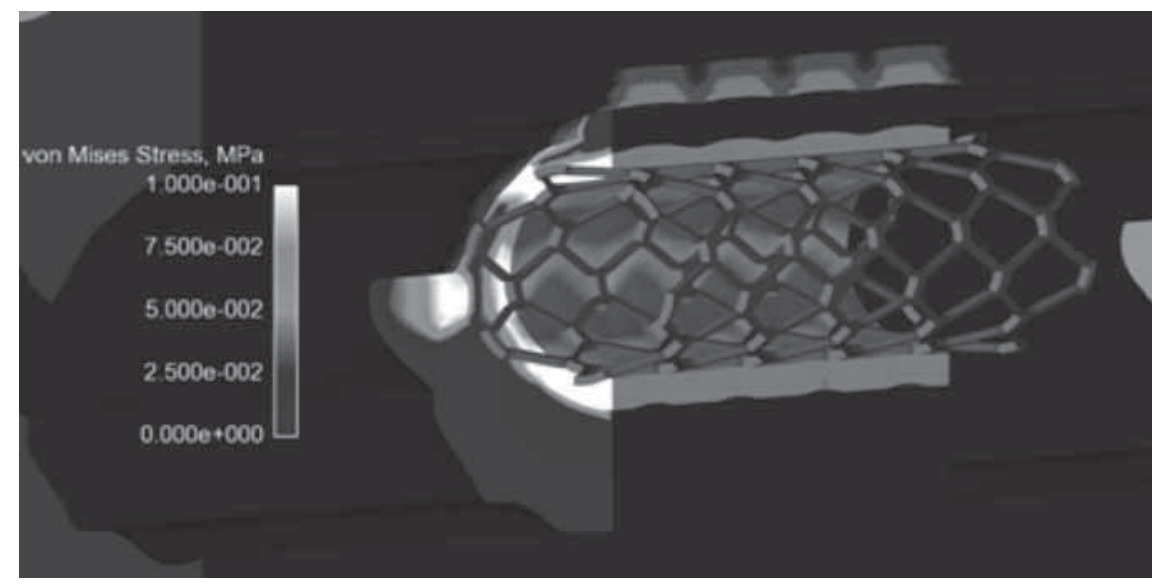

Figure 6a: Arterial/plaque stresses - Complex plaque system.

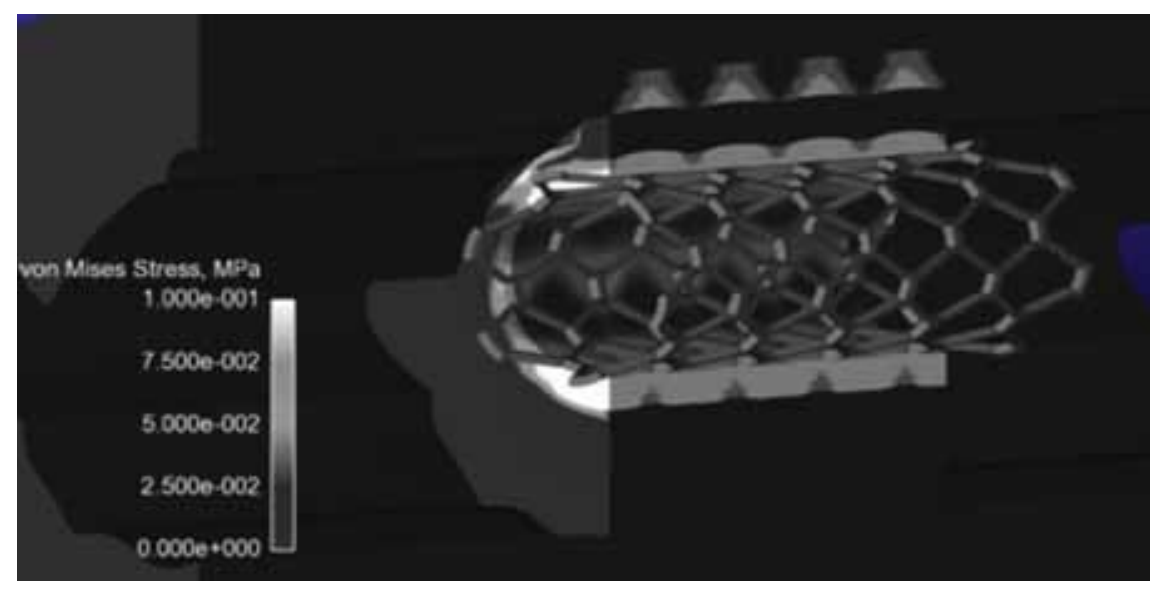

Figure 6b: Arterial/plaque stresses - Homogeneous plaque system.

The clinical significance of the various stresses on vascular injury is unclear. Future studies will be aimed at determining the most appropriate stress to analyze when evaluating vascular injury (von Mises, maximum principal, directional, etc.). The current model does not include the anisotropic behavior of the artery and plaque materials. Additionally, no distinction was made between the passive arterial medium and the active fibers, the orientations of which may vary from inner to the outer layers of the arterial wall. This is currently being included in a more sophisticated model that also includes arterial prestresses.

\section{CLINICAL SIGNIFICANCE OF REPORT}

Concerns that DES interfere with reendothelization and may encourage long-term thrombosis especially in the case of AMI have spurred interest in understanding the mechanisms causing acute deendothelization during the stenting procedure. This model aids in predicting regions of potential plaque fracture and vascular injury. This is an important phenomenon since anti-proliferative drugs 


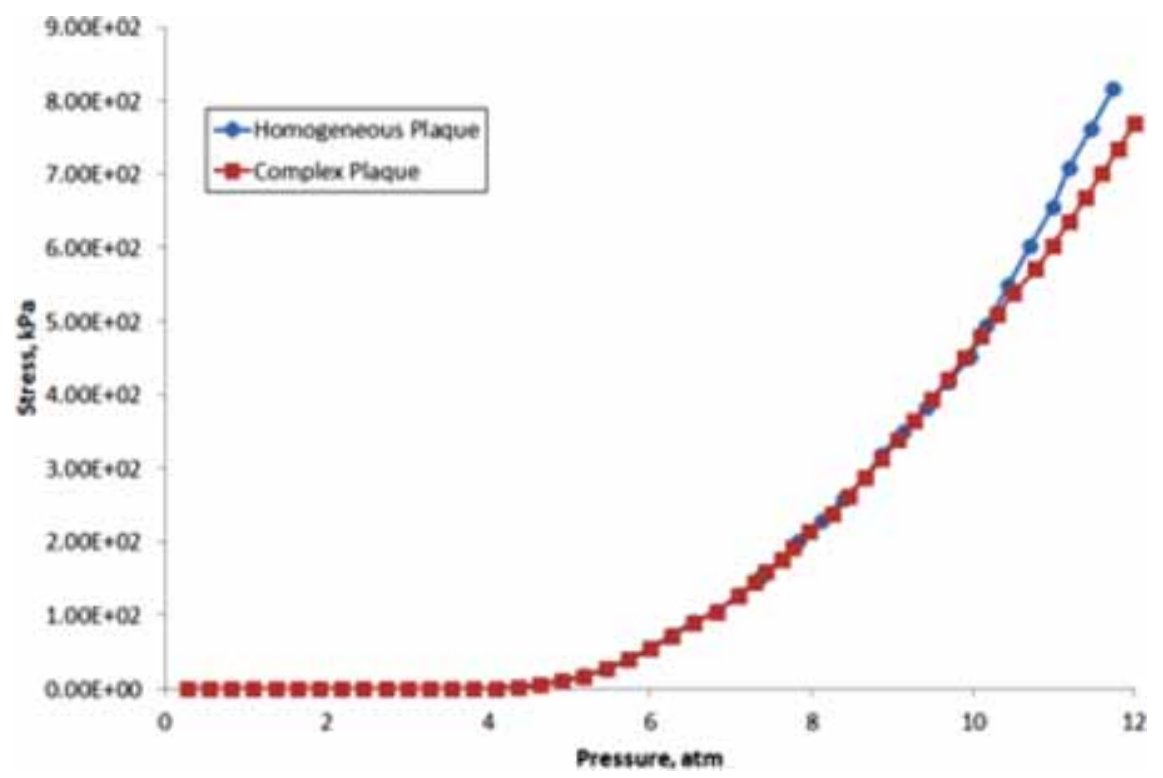

Figure 7: Maximum intimal von Mises stresses.

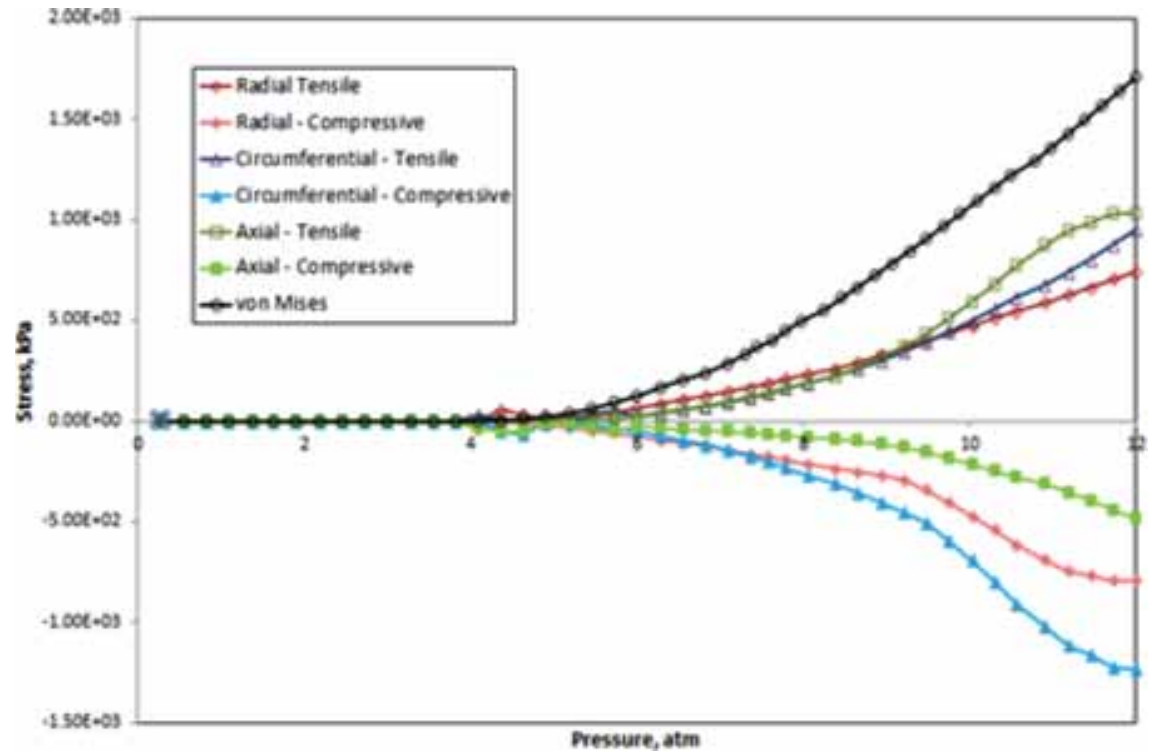

Figure 8: Maximum fibrous cap stresses. 


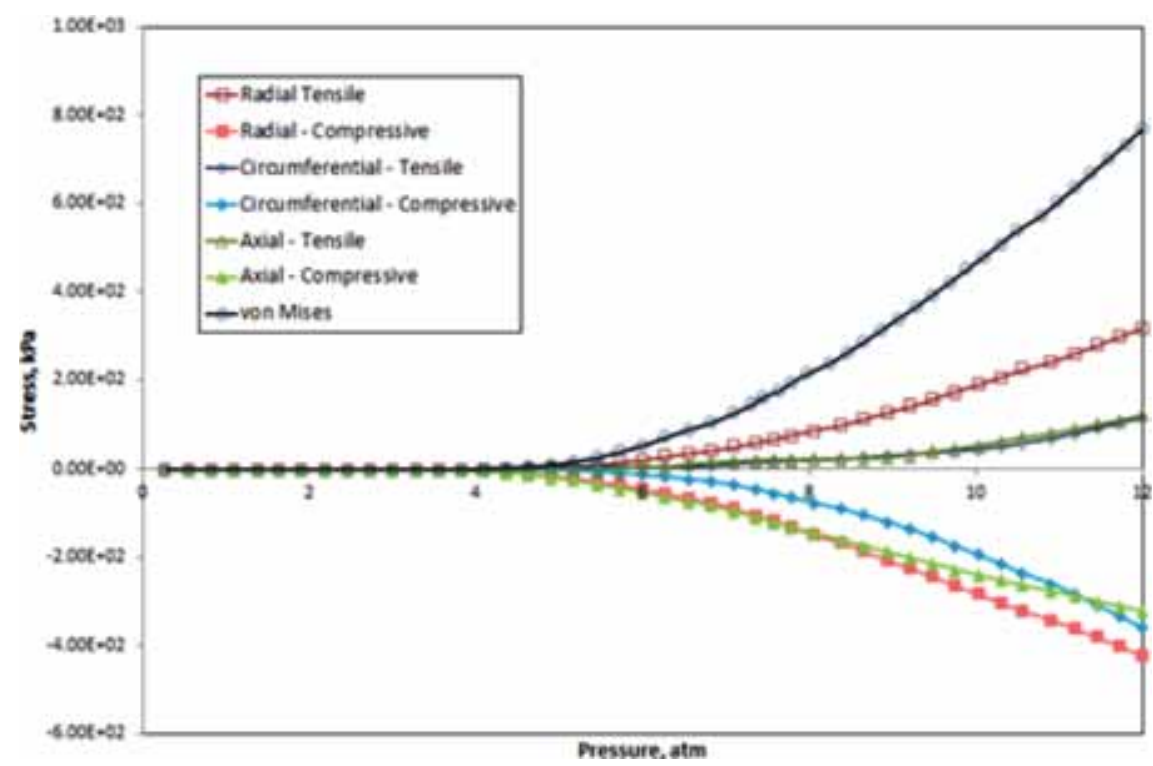

Figure 9: Maximum intimal stresses.

inhibit EC regrowth causing hypersensitivity reactions and increased rates of long-term thrombosis. The capability to predict regions of EC denudation and atherosclerotic plaque rupture during implantation provides a tool to reduce the thrombosis rates of DES.

For carotid artery stenting, computational models may provide a platform to evaluate the susceptibility of atherosclerotic plaque to rupture during the carotid angioplasty and stenting procedure. Combined with MRI reconstructions, these models can be used in cases where the choice between carotid endarterectomy and endovascular angioplasty and stenting is not clear.

The model developed also helps in the prediction of regions of high arterial stresses which may cause vascular injury. Acute superficial and deep vascular injury has been found to be a strong predictor of chronic restenosis. This method provides a predictive tool to evaluate the degree of acute vascular injury of new stent geometries prior to in vivo studies.

\section{REFERENCES}

[1] Weintraub, W.S., The pathophysiology and burden of restenosis. American Journal of Cardiology,100, pp. 3K-9K, 2007. doi: http://dx.doi.org/10.1016/j.amjcard.2007.06.002

[2] Antoniucci, D., Valenti, R., Santoro, G., Bolognese, L., Trapani, M., Cerisano, G. \& Fazzini, P. Restenosis after coronary stenting in current clinical practice. American Heart Journal, 135(3), pp. 510-518, 1998. doi: http://dx.doi.org/10.1016/S0002-8703(98)70329-1

[3] Forrester, J.S., Toward understanding the evolution of plaque rupture: correlating vascular pathology with clinical outcomes. Journal of the American College of Cardiology, 42, pp. 1566-1568, 2003. doi: http://dx.doi.org/10.1016/j.jacc.2003.08.010

[4] Nakazawa, G., Finn, A.V., Joner, M., Ladich, E., Kutys, R., Mont, E.K., Gold, H.K., Burke, A.P., Kolodgie, F.D. \& Vermani, R., Delayed arterial healing and increased late stent thrombosis at culprit sites after drug-eluting stent placement for acute myocardial infarction patients: an autopsy study. Circulation, 118, pp. 1138-1145, 2008. doi: http://dx.doi.org/10.1161/ CIRCULATIONAHA.107.762047 
[5] Joner, M., Finn, A.V., Farb, A., Mont, E.E., Kolodgie, F.D., Ladich, E., Kutys, R., Skorija, K., Gold, H.K. \& Virmani, R., Pathology of drug-eluting stents in humans: delayed healing and late thrombotic risk. Journal of the American College of Cardiology, 48, pp. 193-202, 2006. doi: http://dx.doi.org/10.1016/j.jacc.2006.03.042

[6] Takano, M., Takayoshi, O., Inami, S., Seimiya, K., Sakai, S. \& Mizuno, K., Angioscopic differences in neointimal coverage and in persistence of thrombus between sirolimus-eluting stents and bare metal stents after a 6-month implantation. European Heart Journal, 27, pp. 2189-2195, 2006. doi: http://dx.doi.org/10.1093/eurheartj/ehl181

[7] Waxman, S., Freilich, M.I., Suter, M.J., Shishkov, M., Bilazarian, S., Virmani, R., Bouma, B.E. \& Tearney, G.J., A Case of lipid core plaque progression and rupture at the edge of a coronary stent: elucidating the mechanisms of drug-eluting stent failure. Circulation: Cardiovascular Interventions,3, pp. 193-196, 2010. doi: http://dx.doi.org/10.1161/CIRCINTERVENTIONS. 109.917955

[8] Daemen, J., Wenaweser, P., Tsuchida, K., Abrecht, L., Vaina, S., Morger, C., Kukreja, N., Juni, P., Sianos, G., Hellige, G., van Dombrug, R.T., Hess, O.M., Boersma, E., Meier, B., Windecker, S. \& Serruys, P.W., Early and late coronary stent thrombosis of sirolimus-eluting and paclitaxeleluting stents in routine clinical practice: data from a large two-institutional cohort study. Lancet, 369, pp. 667-678, 2007. doi: http://dx.doi.org/10.1016/S0140-6736(07)60314-6

[9] Lagerqvist, B., James, S.K., Stenestrand, U., Lindback, J., Nilsson, T. \& Wallentin, L., Longterm outcomes with drug-eluting stents versus bare-metal stents in Sweden. The New England Journal of Medicine, 356, pp. 1009-1019, 2007. doi: http://dx.doi.org/10.1056/NEJMoa067722

[10] Stone, G.W., Moses, J.W., Ellis, S.G., Schofer, J., Dawkins, K.D., Morice, M.C., Colombo, A., Schampaert, E., Grube, E., Kiertane, A.J., Cutlip, D.E., Fahy, M., Pocock, S.J., Mehran, R. \& Leon, M.B., Safety and efficacy of sirolimus- and paclitaxel-eluting coronary stents. The New England Journal of Medicine, 356, pp. 998-1008, 2007. doi: http://dx.doi.org/10.1056/ NEJMoa067193

[11] Sianos, G., Papafaklis, M.I., Daemen, J., Vaina, S., van Mieghem, C.A., van Domburg, R.T., Michalis, L.K. \& Serruys, P.W., Angiographic stent thrombosis after routine use of drug-eluting stents in ST-segment elevation myocardial infarction: the importance of thrombus burden. Journal of the American College of Cardiology, 50, pp. 573-583, 2007. doi: http://dx.doi.org/ 10.1016/j.jacc.2007.04.059

[12] Stankovic, G. Liistro, F., Moshiri, S., Briquori, C., Corvaja, N., Gimelli, G., Chieffo, A., Montorfano, M., Finci, L, Spanos, V., Di Mario, C. \& Colombo, A., Carotid artery stenting in the first 100 consecutive patients: results and follow up. Heart, 88, pp. 381-386, 2002. doi: http://dx.doi.org/10.1136/heart.88.4.381

[13] CAVATS Investigators. Endovascularversus surgical treatment in patients with carotid stenosis in the carotid and vertebral artery transluminal angioplasty study (CAVATAS): a randomized trial. Lancet, 357, pp. 1729-1737, 2001. doi: http://dx.doi.org/10.1016/S0140-6736(00) $\underline{04893-5}$

[14] Dietz, A., Berkefeld, J., Theron, J.G., Schmitz-Rixen, T., Zanella, F.E., Turowski, B., Steinmetz, H. \& Sitzer, M., Endovascular treatment of symptomatic carotid stenosis using stent placement: long-term follow-up of patients with a balanced surgical risk/benefit ratio. Stroke, 32, 1855-1859, 2001. doi: http://dx.doi.org/10.1161/01.STR.32.8.1855

[15] Phatouros, C.C., Higashida, R.T., Malek, A.M., Meyers, P.M., Lempert, T.E., Dowd, C.F. \& Halbach, W., Carotid artery stent placement for atherosclerotic disease: rationale, technique, and current status. Radiology, 217, pp. 26-41, 2000. doi: http://dx.doi.org/10.1148/radiology. 217.1.r00oc2526 
[16] van der Vaart, M.G., Meerwaldt, R., Reijnen, M.M., Tio, R.A. \& Zeebreqts, C.J., Endarterectomy or carotid artery stenting:the quest continues. The American Journal of Surgery, 195, pp. 259-269, 2008. doi: http://dx.doi.org/10.1016/j.amjsurg.2007.07.022

[17] Kastrup, A., Schulz, J.B., Raygrotzki, S. Groschel, K. \& Ernemann, U., Comparison of angioplasty and stenting with cerebral protection versus endarterectomy for treatment of internal carotid artery stenosis in elderly patients. Journal of Vascular Surgery, 40, pp. 945-951, 2004. doi: http://dx.doi.org/10.1016/j.jvs.2004.08.022

[18] Hyre, M.R., Squire, J.C. \& Pulliam, R.M., Effects of balloon overhang on stented arteries. 2007 Conference on Modeling in Biology and Medicine, New Forest, England, September 10-12, 2007.

[19] Auricchio, F., Di Loreto, M. \& Sacco, E., Finite element analysis of a stenotic artery revascularization through stent insertion. Computer Methods in Biomechanics and Biomedical Engineering, 4, pp. 249-263, 2001. doi: http://dx.doi.org/10.1080/10255840108908007

[20] Migliavacca, F., Petrini, L., Colombo, M., Auricchio, F. \& Pietrabissa, R., Mechanical behavior of coronary stents investigated through the finite element method. Journal of Biomechanics, 35, pp. 803-811, 2002. doi: http://dx.doi.org/10.1016/S0021-9290(02)00033-7

[21] Petrini, L., Migliavacca, F., Dubini, G. \& Auricchio, F., Evaluation of intravascular stent flexibility by means of numerical analysis. Proceedings of the 2003 Summer Bioengineering Conference, Key Biscayne, FL, June 25-29, pp. 251-252, 2003.

[22] Lally, C., Dolan, F. \& Prendergast, P.J., Cardiovascular stent design and vessel stresses: a finite element analysis. Journal of Biomechanics, 38, pp. 1574-1581, 2005. doi: http://dx.doi.org/ 10.1016/j.jbiomech.2004.07.022

[23] Pericevic, I., Lally, C., Toner, D. \& Kelly, D.J., The influence of plaque composition on underlying arterial wall stress during stent expansion: the case for lesion-specific stents. Medical Engineering \& Physics, 31, pp. 428-433, 2009. doi: http://dx.doi.org/10.1016/j. medengphy.2008.11.005

[24] Hyre, M.R., Pulliam, R.M. \& Squire, J.C., Modeling stent expansion dynamics and blood flow patterns in a stenotic artery. Modelling in Medicine and Biology, ed. C.A. Brebbia, WIT Press: Southampton, UK, pp. 115-129, 2011.

[25] Yang, C., Tang, D., Yuan, C., Hatsukami, Zheng, J. \& Woodard, P.K., In vivo/ex vivo MRIbased 3D non-Newtonian FSI models for human atherosclerotic plaques compared with fluid/ wall-only models. Computer Modeling in Engineering and Sciences, 19, pp. 233-246, 2007.

[26] Yang, C., Tang, D., Kobayashi, S., Zheng, J., Woddard, P., Teng, Z., Bach, R. \& Ku, D.N., Cyclic bending contributes to high stress in a human coronary atherosclerotic plaque and rupture risk. Molecular \& Cellular Biomechanics, 5, pp. 259-274, 2008.

[27] Tang, D., Yang, C., Zheng, J., Woodard, P.K., Saffitz, J.E., Petruccelli, J.D., Sicard, G.A. \& Yuan, C., Local maximal stress hypothesis and computational plaque vulnerability index for atherosclerotic plaque assessment. Annals of Biomedical Engineering, 33, pp. 1789-1801, 2005. doi: http://dx.doi.org/10.1007/s10439-005-8267-1

[28] Tang, D., Yang, C., Zheng, J., Woodard, P.K., Saffitz, J.E., Sicard, G.A., Pilgram, T.K. \& Yuan, C., Quantifying effects of plaque structure and material properties on stress distributions in human atherosclerotic plaques using 3D FSI models. Journal of Biomechanical Engineering, 127, pp. 1185-1194, 2005. doi: http://dx.doi.org/10.1115/1.2073668

[29] Tang, D., Yang, C., Kobayashi, S., Zheng, J., Woodard, P.K., Teng, Z., Billiar, K., Bach, R. \& $\mathrm{Ku}$, D.N., 3D MRI-based anisotropic FSI models with cyclic bending for human coronary atherosclerotic plaque mechanical analysis. Journal of Biomechanical Engineering, 131, pp. 061010, 2009 [Pubmed: 19449964]. doi: http://dx.doi.org/10.1115/1.3127253 
[30] Holzapfel, G.A., Sommer, G. \& Regitnig, P., Anisotriopic mechanical properties of tissue components in human atherosclerotic plaques. Journal of Biomechanical Engineering, 126, pp. 657-665, 2004. doi: http://dx.doi.org/10.1115/1.1800557

[31] Rogers, W.J., Prichard, J.W., Hu, Y.L., Olson, P.R., Benckart, D.H., Kramer, C.M., Vido, D.A. \& Reichek, N., Characterization of signal properties in atherosclerotic plaque components by intravascular MRI. Arteriosclerosis, Thrombosis, and Vascular Biology, 20, pp. 1824-1830, 2000. doi: http://dx.doi.org/10.1161/01.ATV.20.7.1824

[32] Lally, C. \& Prendergast, P.J., An investigation into the applicability of a Mooney-Rivlin constitutive equation for modeling vascular tissue in cardiovascular stenting procedures. Proceedings of the International Congress on Computational Biomechanics, Zaragoza, Spain, pp. 542-550, 2003.

[33] Loree, H.M., Grodzinsky, A.J., Park, S.Y., Gibson, L.J. \& Lee, R.T., Static circumferential tangential modulus of human atherosclerotic tissue. Journal of Biomechanics, 27, pp. 195-204, 1994. doi: http://dx.doi.org/10.1016/0021-9290(94)90209-7

[34] Williamson, S.D., Lam, Y., Younis, H.F., Huang, H., Patel, S., Kaazempur-Mofrad, M.R. \& Kamm, R.D., On the sensitivity of wall stresses in diseased arteries to variable material properties. Journal of Biomechanical Engineering, 125, pp. 147-155, 2003. doi: http://dx.doi. org/10.1115/1.1537736

[35] Lendon, C.L., Davies, M.J., Born, G.V. \& Richardson, P.D., Atherosclerotic plaque caps are locally weakened when macrophages density is increased. Atherosclerosis, 87, pp. 87-90, 1991. doi: http://dx.doi.org/10.1016/0021-9150(91)90235-U

[36] Cheng, G.C., Loree, H.M., Kamm, R.D., Fishbein, M.C. \& Lee, R.T., Distribution of circumferential stress in ruptured and stable atherosclerotic lesions: a structural analysis with histopathological correlation. Circulation, 87, pp. 1179-1187, 1993. doi: http://dx.doi. org/10.1161/01.CIR.87.4.1179

'This article is a reprint of the one presented at Design \& Nature VI Conference, 2012'. 